\title{
A Review of Socio-Cultural Theory
}

\section{Mahbobeh Rahmatirad}

Islamic Azad University, Tehran, Iran

mahbobeh60rahmati@gmail.com

\section{Abstract}

The purpose of this study is to explore Vygotsky's contribution to the socio-cultural theory in the field of education in general. Socio-Cultural Theory, based on Vygotskian thought, is a theory about the development of human cognitive and higher mental function. The theory specially emphasizes the integration of social, cultural and biological elements in learning processes and stresses the socio-cultural circumstances' central role in human's cognitive development. The study aims to elaborate the impact of social-cultural theory in the leaning. The study also reviews implications and applications of socio-cultural theory in second language acquisition. Moreover, this study also critiques the strong points and weakness points of this theory. There are a number of language learning theories which are introduced by researchers in second language research. These theories are based on research and observation in the field of language learning. B. F Skinner's theory of behaviorism, Chomsky's theory of Universal Grammar, Krashen's five Hypotheses, connectionism and Vygotsky's socio-cultural theory have changed people' mind of language learning.
Keywords

socio-cultural theory, second language acquisition

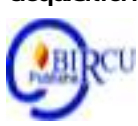

\section{Introduction}

SCT is developed from the work of Vygotsky, his co-workers and successors and this body of work is acknowledged in the term Cultural-Historical Activity Theory. However, most research conducted on L2 learning within this general theoretical framework has used the term Socio-Cultural Theory, and for this reason we will use this term throughout the paper. SCT focuses on children cognitive development and specially emphasizes the integration of social, cultural and biological elements and believes that socio-cultural circumstances play a central role in human's cognitive development and that the process of the development higher mental functionioning is the one by which people internalize or regulate what they learn from social activities through the mediation of symbolic tools and by going through the zone of proximal development, and during this period, language develops from social speech to private speech and then finally to inner speech or verbal thought. Language is the most pervasive and powerful symbolic tool that humans possess to mediate their connection to the world, to each other, and to themselves. That is, Language imbues humans with the capacity to free themselves from the circumstances of their immediate environment and enables them to talk and think about entities and events that are displaced in both time and space, including those events and entities that do not yet exist in the real world.

Through the analysis of applicability of socio cultural theory in SLL, it can be known how theory is applied in English language. The application of socio-cultural theory in L2 classroom clearly lies in the task based approach. There are a number of language learning theories which are introduced by researchers in second language research. These theories are based on research and observation in the field of language learning. 
Mahbobeh Rahmatirad in her article The Effect of Task-Based Syllabus on Iranian EFL Learners asserted:

Also known as the traditional syllabus, it is organized along grammatical items giving primacy to language form. The structural syllabus holds the theory that functionalability arises from structural knowledge. Structural patterns, organized according to such criteria as structural complexity, difficulty, regularity, utility and frequency, are the basic units of learning. It makes an abundant use of highly controlled, tightly structured and sequenced pattern practice drills. It deals with Semantics and sentence types such as statements, questions, interrogatives and grammatically defined types such as simple, compound and complex sentences are seen. Morphology can also be found in structural syllabi such as singular, plural marking; determiners, articles, prepositions, gender markers and so on.

This change was made possible through research and keen observation in the child's language learning development. Vygotsky is very important in second language learning because he introduced the concept of language learning in social interaction. His socio cultural theory basically lays emphasis on the role which is played by social, cultural and historical artifacts in the child's mental development. «From a social-cultural perspective, children's early language learning arises from processes of meaning-making in collaborative activity with other members of a given culture». Lantolf and Thorne defend that the principles of the SCT can also apply to Second Language Acquisition. They explain that «Learning is embedded within social events and occurring as an individual interacts with people, objects, and events in the environment». SLA is concerned with how individuals acquire a certain language other than the native language. SLA is defined by Grass and Selinker as «the study of how learners create a new language system with only limited exposure to a second language. » One of these is behaviorism which proposes that language learning occurs through a series of stimuli and responses and that all learning is the establishment of habits as a result of reinforcement. Skinner is one of the champions of this perspective, who holds that language is a verbal behavior, that is, that the production and comprehension of what is uttered is automatic. Thus, language learners can be made to automatically produce and comprehend language. For behaviorists, no learning occurs if there is no observable change in behavior. They mainly choose to ignore inaccessible mental processes and focus on observable behavior. The cognitivists proposed that human beings are born with a genetic capability that predisposes them to the systematic perception of language around them, resulting in the construction of an internalized system of language. Therefore, SLA is a complete mental process. (Lantolf, JP, 1-26) Mostafa Rahimirad (2019) in his article entitled The Impact of EFL Teachers' Assessment Literacy on Their Assessment Efficiency in Classroom states that, it is true that teachers are at the heart of every educational process in the classroom. Success of any educational reform depends on the teachers', as the implementers of the system, understanding and application of the requirements of the reform. Thus, as attempts have been made to bring about necessary changes and improvements in teaching, learning, and assessment in schools, it is important to explore.

Up to the present time, the bulk of the research into the effects of second language instruction have recorded the linguistic progress of one group exposed to an FonF approach and another exposed to FonFs instruction (Ellis, Basturkmen, \& Loewen, 2002; Loewen, 2003). The present study aims to further explore this area, concentrating on the effect that FonF, and FonM have on the acquisition of a grammatical form with communicative value: the six forms of conditional sentences have been selected. Studies on the effectiveness of focus-on-form instruction have increased greatly and suddenly in 
recent years. Ellis et al (2002) improved Long's (1991) definition of FonF instruction by making the difference between two types: 'Planned focus-on-form' and 'incidental focuson-form.' In many studies, focus on form was the result of prior planning on. (Alahmad, 44)

\section{Methodology}

Sociocultural Theory (SCT) has its origins in the writings of the Russian psychologist L. S. Vygotsky and his colleagues. SCT argues that human mental functioning is fundamentally a mediated process that is organized by cultural artifacts, activities, and concepts (Ratner, 44). This suggests that there is a big difference in the development of the child when he/she is in the company of more knowledgeable other. This difference shows that the child learns actively and promptly in the company of a mentor or a teacher. Vygotsky is to describe the development of the child when he/she works independently, but the difference is made when he/she is supported by the more knowledgeable other. The theory of Vygotsky testifies that the development of the child is possible in the guidance of a teacher, parent or any peer. (Vygotsky, 50)

Mediation is referred as the use of tools and these tools are adopted by the child to resolve a problem or achieve the target. The idea of mediation is treated in different words by Turuk. For example, he describes mediation as the part in the development of the child which is played by more knowledgeable other in his life. Mediation is the use of tools, a part played by other person in the cognitive development of the child. Citing Donato in this context is meaningful because he described scaffolding as a situation which is created by an expert, peer or parent wherein the child can take part and increase his/her current skills and knowledge to higher levels of performance. Simultaneously, Verity looked at scaffolding as cognitive help given to the child that reduces his/her cognitive burden in the learning task. Moreover, Lantolf \& Beckett describe internalization as the process through which learners appropriate social tools of mediation, cultural artifacts, language and utilize it to regulate their cognitive activity. Vygotsky, (1978) defined internalization as Any function in the child's cultural development appears twice, or on two planes. First it appears on the social plane, and then on the psychological plane. First it appears between people as an inter-psychological category, and then within the child as an intrapsychological category (p. 87).

The way Vygotsky (1978) described internalization is to understand the cognitive development of the child which is circled in two planes and these are social and psychological. In social plane, the child develops in the company of parent, mentor or teacher and then he or she becomes independent. Further, Lantolf \& Thorne (2006) stated internalization as the process of learning from social to individual. Similarly, Brown \& Ferrera (1985) treated Internalization in the same vein. First of all, the learner undergoes the process of problem solving activities in the company of others, however, he/ she tends to perform the tasks independently.

\section{Discussion}

\subsection{Drawbacks of Socio-Cultural Theory (SCT)}

The sociocultural perspective, is exactly what its name suggests. It's the idea that the society and groups that an individual belongs to are what influences development, thoughts, and behavior. The application of the ZPD in practice is more problematic. Vygotsky failed to provide much about the effective use of ZPD in classrooms (Shayer, 
2002). Piaget (1995, as cited in Matusov \& Hayes, 2000) suggests that in participation in the activity for which a child is not ready with a more knowledgeable other, leads mainly to imposing the partner' views and will not affect the structures of child's actions (i.e., social constraint). Mitchell \& Myles (2004) claim that most socio-cultural studies of language development within the ZPD have focused on individual lexical items or morpho syntactic features as found in traditional grammar. The concept of Zone of proximal development was critiqued by Lambert \& Clyde (2000) as follows: We feel...that Vygotsky's ZPD presents a restricted view of learning processes and reduces the learner's role to one of passivity and dependence upon the adult (29). They actually failed to consider the application of ZPD in language learning. Vygotsky's descriptions of developmental processes were cited as being vague and speculative. Vygotsky's theory focused more upon the processes through which children develop rather than the characteristics of that children of particular ages are likely to demonstrate. For Vygotsky, cognitive, social, and motivational factors were interrelated in development. (321).

\subsection{Advantages of Socio-Cultural Theory (SCT)}

Psychology is one of the newest sciences. Because it is the science of the mind and behavior, it is also less concrete than some of the other sciences. Over the years, social scientists have developed theories or perspectives based off of their observations, research, and the perspectives of other scientists. Although there is some overlap, each of the major perspectives of psychology is unique. It includes the way learners help each other during second language learning and simultaneously, the way they work together in form of focused activities. Vygotskyan socio-cultural theory and its basic concepts, researchers and practitioners have conducted a number of studies based on SCT. The notion of ZPD is used which engages interaction between expert and novice. The theory presents the positive view of learner and provides meditational tools to promote him or her potential level. A main focus is placed on the active position of learner which is necessary to become a self-regulated learner. Vygotsky revolutionized pedagogy with his thoughtful psychology of child development centered in the socio-cultural perspective Vygotsky's theory provides a solid foundation for examining how children learn before they enter school and how this knowledge relates to concepts learned at school. His socio-cultural approach to educational theory and technology frameworks will afford teachers and learners the pursuit of goals consistent with the best possible personalized learning. Such personalization should address how students learning needs are assessed, what students learn, and how they learn it. This approach also promotes more ways to learn, more subjects to choose from and the flexibility various learning methods would provide. Allowing learners to monitor and manage their own progress will encourage an insatiable appetite for learning (Ballard \& Butler, 222).

Language is one of the most recognizable tools but some tools are more subtle. For example, technology is a tool in western society that less industrialized societies aren't exposed to. An individual that has grown up with complete access to all the latest technology is going to think differently than an individual that has never seen any form of technology. Overall, some behaviors and ways of thinking can only be caused by exposer to specific social and cultural contexts, as this perspective explains. The other strength of the sociocultural perspective is the emphasis on the role of adults in childhood cognitive development through guided participation. Vygotsky introduced the idea that children learn in a zone of proximal development. Meaning the distance between what an individual can do alone and what they can do with guidance and assistance from a capable member of society (Vygotsky, 55). 


\section{a. Teaching through Interaction}

The socio-cultural theorists who work primarily within second language acquisition framework assume that a great deal of language learning takes place through social interaction, at least in part because interlocutors adjust their speech to make it more accessible to learners .The essence of language is to be able to communicate one's thoughts and feelings to another person. This concept of communication is one of the foundations of SCT in language learning, which is one of the second language acquisition theory modules. SCT believes that language can be acquired easily by allowing the students to socialize and interact either with other learners or with the speakers of the language they are learning. The interaction should also be within the context of the language being learned. Ideally, SCT suggests that the best way to acquire a language is to learn it from the place it is being used and to interact with native speakers. In the context of the classroom, SCT in second language acquisition can be practiced through social activities that simulate the cultural context of the language. Aside from the classic role playing, here are some activities for strengthening the communication skills of second language learners based on SCT. (Donato, R., 27-50)

\subsection{Differences of SCT with Cognitive Theory}

It might help provide an overview of SCT by comparing it with the cognitive approach because they correlate with each other. These two approaches are both interested in how learners access linguistic knowledge, that is, linguistic performance rather than linguistic competence that is the focus of UG theorists. However, the theorists of these two approaches hold very different views towards the learning process. Firstly, cognitive approach researchers believe that the SLA process can be better understood by working out how the brain processes and learns new information.

Finally, from the perspective of research methods, cognitive researchers rely on the post-instructional testing to examine learning, whereas researchers of SCT look for evidence through shared practices of discourse with peers or experts. By contrast cognitivism expects more cognitive participation of language learners in the process of learning and contends that learners make use of their mental processes. Grounded upon SCT, social interaction and cooperative learning are paramount in constructing both cognitive and emotional images of reality. Human learning is a continuous reciprocal interaction of cognitive, behavioral and environmental factors.

\section{a. Universal Grammar Theory}

According to Chomsky $(1995,7)$, the main objective for researchers is to seek "best theories" in the search for better understanding the natural world. Whether the idea of Universal Grammar is the best explanation for how language acquisition functions is not for this paper to decide, but its theoretical framework and arguments highlight that there are still unanswered questions in the field of linguistics. The strength of the arguments for Universal Grammar are hard to ignore, which, even if one disagrees with the theory, proves that there is still much to explore in the way we as human beings acquire and use the languages we speak. The vagueness of the arguments against UG may in fact lend more strength to the idea of UG as the best theory, since UG is able to account for many of the things that critics cannot. There are two main arguments for the existence of Universal Grammar. Having looked at arguments in favor of Universal Grammar. The first argument claims that the infinitely productive and creative nature of the language that the child acquires cannot be explained merely by means of sensory input, as it is impossible for a child to gain sufficient linguistic data to be able to speak as they do. The second 
argument continued from the first, focusing more directly on the innate grammatical structures which are presented in the theory of UG, concluding that even though children do not receive enough linguistic input to be able to sufficiently "learn" grammatical structures such as the use of auxiliaries in English, they still make virtually no mistakes in the area.

\section{b. Behaviorism Theory}

SCT's ideology is quite different from that of the behaviorism and cognitivism. In behaviorism it is implied that language learning occurs when individuals provide conditioned responses to stimuli and that language learning is a process of habit formation. By contrast cognitivism expects more cognitive participation of language learners in the process of learning and contends that learners make use of their mental processes. Many critics argue that behaviorism is a one-dimensional approach to understanding human behavior and that behavioral theories do not account for free will and internal influences such as moods, thoughts, and feelings. Behaviorism does not account for other types of learning, especially learning that occurs without the use of reinforcement and punishment. People and animals are able to adapt their behavior when new information is introduced, even if a previous behavior pattern has been established through reinforcement. Behaviorism is based upon observable behaviors, so it is easier to quantify and collect data and information when conducting research. Effective therapeutic techniques such as intensive behavioral intervention, behavior analysis, token economies, and discrete trial training are all rooted in behaviorism. These approaches are often very useful in changing maladaptive or harmful behaviors in both children and adults.

\section{c. Connectionism Theory}

Connectivism is a theoretical framework for understanding learning in a digital age.

It emphasizes how internet technologies such as web browsers, search engines, wikis, online discussion forums, and social networks contributed to new avenues of learning. Connectivism is a learning theory that explains how Internet technologies have created new opportunities for people to learn and share information across the World Wide Web and among themselves. These technologies include Web browsers, email, wikis, online discussion forums, social networks, YouTube, and any other tool which enables the users to learn and share information with other people. A key feature of connectivism is that much learning can happen across peer networks that take place online. In connectivist learning, a teacher will guide students to information and answer key questions as needed, in order to support students learning and sharing on their own. Students are also encouraged to seek out information on their own online and express what they find. A connected community around this shared information often results. (Siemens,3-10)

Siemens (2006b) suggests:

Instead of modelling our knowledge structures as hierarchical or flat, confined belief spaces, the view of networks enables the existence of contrasting elements selected on the intent of a particular research or learning activities. If the silos of traditional knowledge classification schemes are more fluid, perhaps the individual elements of different theories can be adopted, as required, to solve more nuances of learning problems. When the theory does not require adoption in its fullest (i.e. interpretivism or positivism), the task of seeking knowledge becomes more salient. (p. 29) 


\section{d. Input Processing Theory}

The importance of input has always been recognized in the field of second language acquisition and hence one of the key questions addressed by researchers is how second language (L2) learners process input when listening or reading. Learners seem to process input for meaning before they process it for form. Learners seem to parse sentences by assigning subject or agent status to the first noun or pronoun they encounter in a sentence. Learners should be exposed to meaningful input that contains many instances of the same grammatical meaning-form relationship. Training helps learners process input correctly and efficiently and consequently increases the intake of target language by the learners. Improved feedback treatments give comprehensible access for language learners Input and proof positive. Enhancement of inputs helps learners pay attention to input grammatical forms. Processing strategies in favor of more optimal ones. Thus, PI aims to increase the likelihood that L2 learners will attend to form in the input by altering those undesirable information about the target structure and 'are informed about a particular processing strategy that may negatively affect their pick $\neg$ ing up of the form' (Van Patten, 2005, p. 273). This instruction is followed by Structured Input (SI) activities, in which Van Patten states that Input is manipulated in particular ways so that learners become dependent on form and structure to get meaning and/or to privilege the form or structure in the input so that learners have a better chance of attending to it. (VanPatten, 2005, p. 273)

\subsection{The Three levels of Adequacy of Sociocultural Theory}

Observational adequacy: From a social-cultural perspective, early language learning for children results from meaning-making processes in collective interaction with other members of a specific community. SCT also strongly claims that the process of language acquisition is the process in which an individual's external speech is gradually internalized and combined with thought by means of communicative activities.

Descriptive adequacy: The socio-cultural theorists who work primarily within second language acquisition framework assume that a great deal of language learning takes place through social interaction, at least in part because interlocutors adjust their speech to make it more accessible to learners. The essence of language is to be able to communicate one's thoughts and feelings to another person. This concept of communication is one of the foundations of SCT in language learning, which is one of the second language acquisition theory modules. SCT believes that language can be acquired easily by allowing the students to socialize and interact either with other learners or with the speakers of the language they are learning. The interaction should also be within the context of the language being learned.

Explanatory adequacy: SCT suggests that the best way to acquire a language is to learn it from the place it is being used and to interact with native speakers. In the context of the classroom, SCT in second language acquisition can be practiced through social activities that simulate the cultural context of the language. SCT also strongly claims that the process of language acquisition is the process in which an individual's external speech is gradually internalized and combined with thought by means of communicative activities. The detailed steps are from External Speech (without thought) to Egocentric Speech (beginning to combine with thought) and to Inner Speech (becoming verbal thought). The final results of second language acquisitions are that people are able to think about things with the target language and then language and thought are combined together finally becoming verbal thought. Sometimes, the relationship between speech and thinking can be expressed by two intersecting circles. The shared area is called verbal thought. 


\section{Conclusion}

The study concludes with the idea that it was really surprise for researchers with the idea that socio cultural factors are necessary for the cognitive development of the child in language learning. His genuine contribution to socio-cultural theory and his challenging ideas into this theoretical framework have a great place in the field of education, psychology and applied linguistics. Broadly speaking, the application of these ideas is a matter of great significance. Second language acquisition has undergone major changes during recent decades. Different theoretical perspectives made language teachers and curriculum developers behave and think differently as to how language learners should learn a second language. We must be well aware that the knowledge of SCT can also be useful for teachers to discover and create ways to set up tasks and activities which can allow for the facilitation of language learning. However, SCT presented another ideology of learning, which appeared in the field of learning with two perspectives: cognitive and social. Therefore, SCT provides a new perspective on the process of SLA, in which learners are encouraged or required to think as well as speak in the target language, that is to say, language and thought should be closely connected with each other.

\section{References}

Alahmad, Mana. The Role of Form-Focused Instruction on Foreign Language Learners. Budapest International Research and Critics in Linguistics and Education (BirLE) Journal Volume 2, No 4, November 2019, Page: 44-53. www.bircujournal.com/index.php/birle

Brown, A. I., \& Ferrera, R. A. (1985). Diagnosing zones of proximal development. In J. Wertsch (Ed.), Culture communication and cognition: Vygotskian perspective (pp. 273-305). Cambridge: Cambridge UniversityPress.

Bruner, J. S. (1978). The role of dialogue in language acquisition. In A. Sinclair, R. J. Jarvelle, \& W. J. M. Levelt (Eds.), The Child's Concept of Language (pp. 241-256). New York: Springer-Verlag.

Donato, R. (2000). Socio-cultural contributions to understanding the foreign and second language classroom. InJ. P. Lantolf (Ed.), Socio-cultural theory and second language learning (pp. 27-50). Oxford: OxfordUniversity Press.

Lantolf, J. P. (2000). Introducing sociocultural theory. In J. P. Lantolf (Ed.), Sociocultural theory and second language learning (pp. 1-26). Oxford: Oxford University Press.

Lantolf, J. P., \& Beckett, T. G. (2009). Sociocultural theory and second language acquisition. Language Teaching,42(04), 459-475. https://doi.org/10.1017/S0261444809990048

Rahmatirad, Mahbobeh. The Effect of Task-Based Syllabus on Iranian EFL Learners. Budapest International Research and Critics in Linguistics and Education (BirLE) Journal Volume 2, No 4, November 2019, Pages: 32-43.www.bircujournal.com/index.php/birle.

Rahimirad, Mostafa. The Impact of EFL Teachers' Assessment Literacy on Their Assessment Efficiency in Classroom. Britain International of Linguistics, Arts and Education (BIoLAE) Vol. 1, No. 1, July 2019, Page: 9-17

Siemens, G. (2005). Connectivism: A learning theory for the digital age. International Journal of Instructional Technology and Distance Learning, 2(1), 3-10.

Turuk, C. M. (2008). The relevance and implications of Vygotsky's socio-cultural theory in the second language classroom: ARECLS, 5, 244-262. 
Vygotsky, L. S. (1978). Mind in society: The development of higher psychological Processes. Cambridge, MA:Harvard University Press.

VanPatten, B. (2003). From input to output: A teacher's guide to second language acquisition. New York: McGraw-Hill.

Vygotsky, L. S. (1987). Thinking and speech. New York: Plenum Press.

Vygotsky, L. S. (1997). Educational Psychology. Florida: St. Lucie Press.

Wertsch, J. V. (1998). Mind as Action. Oxford: Oxford University Press.

Williams, M., \& Burden, R. (1997). Psychology for language teachers, a social constructivist approach. UK: Cambridge University Press. 